Research Article

\title{
Driving Factor Analysis of Carbon Emissions in China's Power Sector for Low-Carbon Economy
}

\author{
Dan Yan, ${ }^{1,2}$ Yalin Lei, ${ }^{1,2}$ and $L i L^{1,2}$ \\ ${ }^{1}$ School of Humanities and Economic Management, China University of Geosciences, Beijing 100083, China \\ ${ }^{2}$ Key Laboratory of Carrying Capacity Assessment for Resource and Environment, Ministry of Land and Resources, \\ Beijing 100083, China
}

Correspondence should be addressed to Yalin Lei; leiyalin@cugb.edu.cn

Received 14 September 2016; Revised 16 February 2017; Accepted 22 February 2017; Published 13 March 2017

Academic Editor: Risto Lahdelma

Copyright (C) 2017 Dan Yan et al. This is an open access article distributed under the Creative Commons Attribution License, which permits unrestricted use, distribution, and reproduction in any medium, provided the original work is properly cited.

\begin{abstract}
The largest percentage of China's total coal consumption is used for coal-fired power generation, which has resulted in the power sector becoming China's largest carbon emissions emitter. Most of the previous studies concerning the driving factors of carbon emissions changes lacked considerations of different socioeconomic factors. This study examines the impacts of eight factors from different aspects on carbon emissions within power sector from 1981 to 2013 by using the extended Stochastic Impacts by Regression on Population, Affluence and Technology (STIRPAT) model; in addition, the regression coefficients are effectively determined by a partial least squares regression (PLS) method. The empirical results show that (1) the degree of influence of various factors from strong to weak is urbanization level (UL) $>$ technology level $\left(T_{1}\right)>$ population $(\mathrm{P})>$ GDP per capita $(\mathrm{A})>$ line loss $\left(T_{2}\right)>$ power generation structure $\left(T_{3}\right)>$ energy intensity $\left(T_{4}\right)>$ industry structure (IS); (2) economic activity is no longer the most important contributing factor; the strong correlation between electricity consumption and economic growth is weakening; and (3) the coal consumption rate of power generation had the most obvious inhibitory effect, indicating that technological progress is still a vital means of achieving emissions reductions.
\end{abstract}

\section{Introduction}

Since the 1960s, climate change has become a scientific issue that has been widely concerned. The world has reached a consensus on limiting the rise in temperature to 2 degrees as a long-term goal to address climate change. According to the United Nations Commission on Climate Change (UNCCC), greenhouse gases (GHGs) concentrations in the atmosphere must be controlled at $450 \mathrm{ppm}$ or less, and the target of keeping global warming to no more than about 2 degrees Celsius is expected to be achievable. The fifth assessment report released by Intergovernmental Panel on Climate Change (IPCC) claimed that the massive use of fossil fuel based on human activity is the main cause of increasing GHGs in recent years, especially $\mathrm{CO}_{2}$ emissions. From 1990 to 2012, a substantial increase in global coal production resulted in the power sector-generated $\mathrm{CO}_{2}$ emissions doubling, with this sector becoming the world's largest carbon emissions sector, accounting for $42 \%$ [1].

Over the past 30 years, China's economic growth has been close to $10 \%$ on average; energy consumption and $\mathrm{CO}_{2}$ emissions have increased dramatically, and China has become the largest carbon emitter worldwide, accounting for $25 \%$ of the global carbon emissions [2]. The large amount of $\mathrm{CO}_{2}$ emissions prompted China to recognize its international responsibilities; in 2009, the Chinese government claimed that it would strive to cut its carbon intensity by $40-45 \%$ before 2020, compared with that in 2005; in addition, a formal commitment on reaching the peak of its GHGs emissions by approximately 2030 while striving to peak earlier was also made by the Chinese government in 2014 [3]. $\mathrm{CO}_{2}$ emissions are closely related to fossil energy consumption; thus, the peak emission goal formed the reverse transmission mechanism for coal consumption, indicating that the amount 


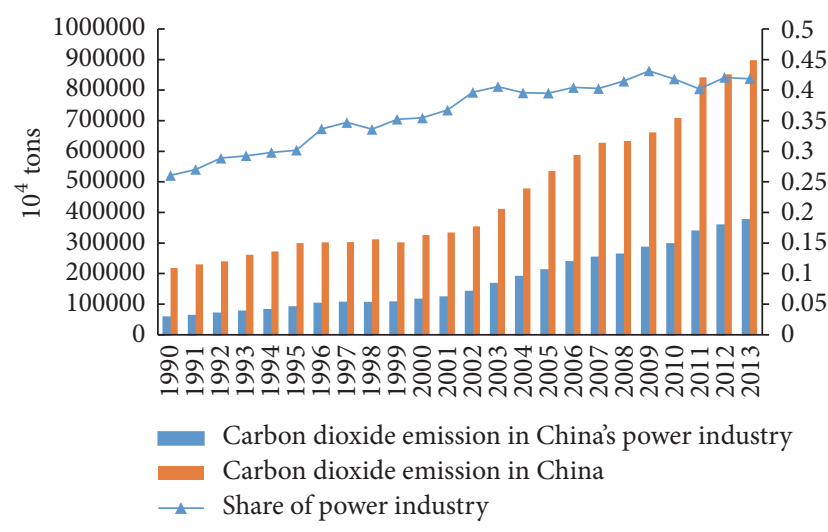

Figure 1: The carbon dioxide from China's power sector (19902013).

of coal consumption in China in 2020 and 2030 must be less than 3.8 billion tons and less than 3.4 billion tons, respectively [4].

Electricity generation is mainly dominated by coal in China; coal consumption for the power sector accounted for $44.73 \%$ of the total. Based on our estimations, there was a dramatic growth in the carbon emissions of power sector between 1981 and 2013 (see Figure 1); to be more specific, it had reached the peak at $3758 \mathrm{MT}$ in 2013, accounting for $41.8 \%$ of China's total carbon emissions, which also resulted in this sector becoming China's top carbon dioxide emitter.

The 13th Five-Year Plan states that the carbon emissions from power and other key industries should be controlled effectively and that development areas should take the lead in achieving peak emissions targets [14]. Understanding the driving factors involved in economics, society, and industry of emissions is essential towards giving policies for the future development of the power sector.

Over the past 30 years, the full-calibre installed powergenerating capacity in China has increased by a factor of 22.7 times, from 60 gigawatts (GW) in 1980 to $1360 \mathrm{GW}$ in 2014, and power consumption has increased by a factor of 18.7 times, from 295 TWh in 1980 to 5523 TWh in 2014 [15]. However, this country is entering a slower economic growth, moving from an economy driven by investment and exports to one mainly relying on consumption and services; the growth of electricity demand has also been slowing; the growth of electricity consumption has also been undergoing a transition from depending on energy intensiveness to emerging industries, service industries, and residential electricity demands. Considering the social and economic factors influencing carbon emissions from the power sector under conditions of new urbanization and industrialization processes, we must determine which policies will have better effects.

The structure of this paper is mainly divided into five sections, as follows: Section 1 is the introduction. Section 2 reviews the previous work on this study. Section 3 presents the calculation of carbon emissions from the power sector, the basic STIRPAT model and its extended form, and the PLS method to manage multicollinearity. Section 4 describes the main results and provides a discussion and Section 5 is conclusions and potential policy implications.

\section{Literature Review}

2.1. Research on Driving Factors behind Power Sector. As the main sector for energy processing and conversion, the power sector plays a key role in achieving low-carbon economy. The changes in carbon emissions from the power sector are affected by multiple factors. Previous scholars have used different methods and thus drawn different conclusions. Malla [6] employed the LMDI model for studying the effects of three factors influencing carbon emissions within electricity industry from 7 countries; the results showed that, during period 1990-2030, the effect of the electricity production remains the major factor responsible for rise in emissions. LMDI method was also used by Shrestha et al. [5] to conclude that the dominant factor behind the performances of $\mathrm{CO}_{2}$ emissions varies from one country to another. Decomposition model was used by Steehhof and Weber [7] to estimate the factors affecting the trends of Canadian electricity industry's carbon emissions, while the authors took considerations of weather and government policies. A factors decomposition model of $\mathrm{CO}_{2}$ emission changes from China's electricity production was built by Hou and Tan [8] based on LMDI method; the changes in carbon emissions by electricity production were decomposed into five factors: income effect, electricity production intensity, power production structure, population effect, and coal consumption rate. Zhang et al. [9] used LMDI method to find the rules of influence factors of carbon emissions and finally pointed out that economic activities were the main contributing factors, but the efficiency of electricity production was vital in reducing carbon emissions. Different from Zhang et al. [9], Yang and Lin [11] extended the sample range, indicating that EI (electricity intensity) and EAs (economic activities) are the main factors driving $\mathrm{CO}_{2}$ emissions changes from the power industry, accounting for $42.33 \%$ and $57.05 \%$ of the total increase during 1985-2011; they also confirmed that EE (energy efficiency) in the power industry plays a key role in energy savings and emissions reductions. Zhao et al. [10] applied autoregressive-distributed lag (ARDL) model to estimate the $\mathrm{CO}_{2}$ emissions from power industry in China from 1980 to 2010; the results showed that equipment utilization hours had the most significant impact on $\mathrm{CO}_{2}$ emissions; in addition, the added value of the industry had a positive influence in the short term, and the pressures created by $\mathrm{CO}_{2}$ emission reduction are an important motivator of technological progress within the power industry.

Socioeconomic drivers related to $\mathrm{CO}_{2}$ emissions in Iran's power sector are fully considered by Noorpoor and Kudahi [13]; the outputs of the STIRPAT model showed that they both had played a positive role in increasing these emissions. Karmellos et al. [12] used an LMDI model to investigate the key drivers behind carbon emissions within the power sectors in all of the European Union countries from 2000 to 2012; in addition, the sample data were divided into two stages to detect the effects of the economic crisis. 
Most of the previous studies have adopted the LMDI model, as it has a strong theoretical basis and adaptability, is easy to use, and offers better results interpretation. LMDI has been widely used in different countries, sectors, and environmental problems [16-18]; however, the factors that can be investigated by the index decomposition method still have some limitations. The decomposition factors are similar, and many other factors cannot be included in the analysis. In the past research, there have been few studies unraveling the nature of the relationship between $\mathrm{CO}_{2}$ emissions and socioeconomic factors, and the sample data lagged behind; the explanatory variables were selected from one particular point of view, which paid insufficient attention to social, economic, and household consumption (see Table 1).

\subsection{The Application of the STIRPAT Model to $\mathrm{CO}_{2}$ Emissions.} GHGs emissions from human activities are mainly affected by drivers, such as population, affluence, and technological progress; on this issue, the IPAT model and its derivative STRIPAT model or deformation are among the mainstream research methods with the characteristics of flexible design parameters and targeted research problems. Li et al. [19] combined the path analysis with STIRPAT model to discuss the driving factors behind China's growing carbon emissions and got the contributing degree of the factors. Similar studies were performed by Lin et al. [20]. This model has also been applied by Fan et al. [21] to explore the effects of population, affluence, and technology on the environmental impact of countries with different income levels. In an empirical analysis on the factors influencing $\mathrm{CO}_{2}$ emissions in Beijing, Wang et al. [22] introduced R\&D output to represent the technology level and finally concluded the emphasis of carbon emissions reduction.

When multicollinearity exists between variables, a few scholars have applied ridge regression to handle it [23-25]. However, due to subjectivity, the method cannot accurately reflect the results. As the association between variables tends to be complex and can be two-way, the traditional ordinary least square (OLS) method sets too many restrictions. The partial least squares (PLS) method can better solve these problems; specifically, it includes more information about independent variables in the algorithm; and these characteristics have been gaining favour by scholars in recent years $[26,27]$.

Compared with other models, the STIRPAT model is more reliable and informative. People can choose different indicators to reflect the development degree in a region; therefore, this model could be better employed for analysis of the driving factors at different levels of the environment in a region. According to the above review, the research based on STIRPAT models has focused on the national level or the city level, and there is a paucity of studies applying the STIRPAT model to the power industry. This paper contributes to closing this gap.

With the acceleration of urbanization, China's energy consumption has gradually turned from the production type to the consumer type [28], which not only has led to economic and social changes but also has affected lifestyles and energy consumption changes. Few studies have fully considered the macroeconomic and social background regarding analysis of the drivers of emissions behind Chinas power sector, for example, the population, residents' income, and the urbanization level. China has experienced an adjustment of industrial structure upgrades, economic growth is slowing, and people's living conditions have gradually improved; then the impact of these factors cannot be ignored.

\section{Methods and Data}

3.1. Data Collection. The paper adopted the data interval 1981-2013, and the data for total population and urbanization rate were collected from the China Statistic Yearbook (1982-2013); we used 1981 as the base year, and the GDP per capita was converted to constant prices.

The data for the proportion of second industries comes from the China Energy Statistics Yearbook (1982-2014). The data for the proportion of thermal power generation over total power generation, the line loss rate, the coal consumption rate of power plants over $6000 \mathrm{~kW}$, and electricity consumption per unit of GDP were drawn from the China Electricity Council (CEC).

3.2. Calculation of Carbon Emissions from China's Power Sector. The IPCC [29] provided specific principles and methods for calculating GHGs emissions in 2006, which have been widely used. The calculation of $\mathrm{CO}_{2}$ emissions from China's power sector is based on the IPCC method 1, combining the related parameters from the guide for the compilation of provincial GHG inventories, during 1981-2013. Assuming that no $\mathrm{CO}_{2}$ emissions were generated in the process of power consumption, the $\mathrm{CO}_{2}$ emissions were calculated from the perspective of power production.

$$
\mathrm{CO}_{2}=\sum_{i=1}^{8} \mathrm{CO}_{2, i}=\sum_{i=1}^{8} E_{i} \times \mathrm{NCV}_{i} \times \mathrm{CEF}_{i} \times \mathrm{COF}_{i} \times \frac{44}{12} .
$$

Because there is no separate category of the power sector in China's statistical yearbooks, the steam/hot water production and supply sector were used as a substitute for the power sector. In (1) $E$ represents energy consumption, the data of which in power production process comes from China energy statistical yearbook (1982-2014), and $i$ represents energy types, including coal, coke, crude oil, gasoline, kerosene, diesel oil, fuel oil, or natural gas. NCV represents the average low caloric value; $\mathrm{CEF}$ represents the coefficient of carbon emissions per unit of heat; COF represents the carbon oxidation factor, that is, the energy-burning carbon oxidation rate; and 44 and 22 represent the molecular weights of carbon dioxide and carbon, respectively. Referring to the actual situation of China, among the above parameters, NCV was adopted from the appendix of the "China Statistical Yearbook 2013"; CEF and COF were adopted from the "Provincial Greenhouse Gas Inventory Preparation Guide."

3.3. The STIRPAT Model. The classic environmental pressure evaluation model (IPAT model) was raised by the American 


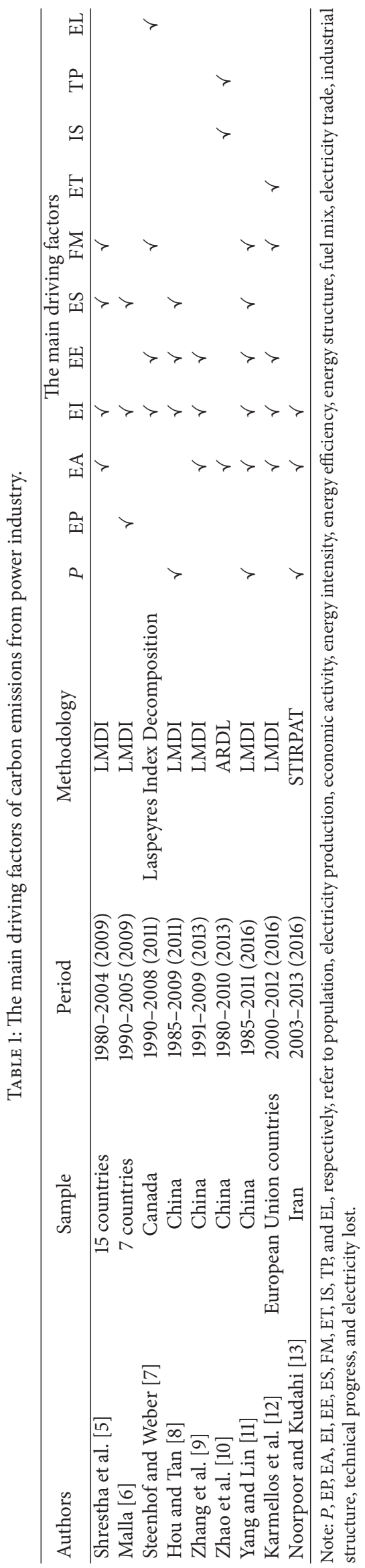


TABLE 2: Description of the model variables.

\begin{tabular}{|c|c|c|c|}
\hline Variable & Symbol & Definition & Unit \\
\hline Carbon emissions & $I$ & Power sector related carbon emissions & $10^{4}$ ton \\
\hline Population & $P$ & Total population & $10^{4}$ units \\
\hline Economic level & $A$ & GDP per capital $(1981=100$ constant $)$ & yuan \\
\hline Coal consumption rate & $T_{1}$ & $\begin{array}{l}\text { Standard coal consumption per unit power } \\
\text { generation }\end{array}$ & $\mathrm{g} / \mathrm{kWh}$ \\
\hline Line lose rate & $T_{2}$ & $\begin{array}{l}\text { Proportion of the loss of electricity over the } \\
\text { total electricity power generation in power grid }\end{array}$ & $\%$ \\
\hline Power generation Structure & $T_{3}$ & $\begin{array}{l}\text { Proportion of thermal power generation over } \\
\text { total power generation }\end{array}$ & $\%$ \\
\hline Energy intensity & $T_{4}$ & Power consumption per unit of GDP & kWh per $10^{4}$ yuan \\
\hline Industrial structure & IS & $\begin{array}{l}\text { Proportion of second industry* accounting for } \\
\text { total GDP }\end{array}$ & $\%$ \\
\hline Urbanization level & $\mathrm{UL}$ & $\begin{array}{l}\text { Proportion of city population over the total } \\
\text { population }\end{array}$ & $\%$ \\
\hline
\end{tabular}

* "Second industry" here simply refers to "industry; construction" in China Statistical Yearbooks.

ecologist Ehrlich and Holdren [30] in the 1970s; the three factors that directly affect the environment were the population $(P)$, affluence $(A)$, and technology $(T)$. Establishing the identical relative formula of four variables,

$$
I=P \times A \times T \text {. }
$$

This formula provides a conceptual framework for the relationships among the four variables with a simple theory and form. There are deformations of this equation: $I=$ PBAT [31] and $I=$ PACT [32]; however, both of these models can only estimate the proportionate impact. Dietz and Rosa [33] proposed the improved nonlinear STIRPAT model, which abandoned the assumption of unit elasticity, so as to facilitate the empirical analysis, and it can realize the assessment of the environmental pressure by various types of driving factors through the decomposition of technical items.

$$
I_{t}=\alpha P_{t}^{b} A_{t}^{c} T_{t}^{d} e_{t}
$$

For quantitative analysis of sequence data, the model was changed into the logarithmic form:

$$
\ln I_{t}=\alpha+b \ln P_{t}+c \ln A_{t}+d \ln T_{t}+e_{t},
$$

where $\alpha$ is the constant term, $t$ indicates the period, $e$ is the error term, and $b, c$, and $d$ stand for the elastic coefficients of the independent variables, indicating the percentage change in environmental impact caused by the percentage changes in $P, A$, and $T$. Regardless of whether the model is the traditional IPAT model or the random STIRPAT model, $P, A$, and $T$ can be decomposed according to the specific circumstances. Therefore, formula (4) is reformulated as formula (5):

$$
\begin{aligned}
\ln I_{t}= & \alpha+b \ln P_{t}+c \ln A_{t}+d \ln T_{i t}+f \ln T_{2 t} \\
& +g \ln T_{3 t}+h \ln T_{4 t}+j \ln \mathrm{IS}+k \ln \mathrm{UL}+e_{t} .
\end{aligned}
$$

The variables in formula (5) are defined as follows: $I$ represents carbon emissions, and $P$ represents the population size, which is different from [10], who omitted the population factor. A represents economic level indicated by GDP per capita, and $T$ stands for the technology level, which has been decomposed into $T_{1}, T_{2}, T_{3}$, and $T_{4}$. UL and IS represent the urbanization level and industrial structure (see Table 2).

3.4. Multicollinearity Testing. Multicollinearity refers to accurate or approximately accurate linear relationships between explanatory variables. There are two types of results: first, if there is perfect collinearity between various explanatory variables, the regression coefficients are uncertain, but this situation is very rare in reality; second, if the collinearity is high but not complete, the estimate of the regression coefficients has a tendency to result in large standard errors. The correlation coefficient matrix of each of two variables (see Table 3) showed that a few correlation coefficients between the various explanatory variables can be high; for further inspection, the variance inflation factor (VIF) method was used to examine the multicollinearity between variables. The VIF is the variance inflation factor calculated by multiple determination coefficients determined by auxiliary regression of multiple explanatory variables. When the VIF is larger, it explains that the multicollinearity among the variables is stronger. When $\mathrm{VIF} \geq 10$, indicating that there exists serious multicollinearity between explanatory variables, it can unduly influence the results of least squares estimation. In this study, the VIFs of the variables $\ln P, \ln A, \ln T_{1}, \ln T_{2}$, and $\ln \mathrm{UL}$ are far greater than 10 , so there exists a serious problem of multicollinearity (see Table 4 ). As shown in the illustration, the variables $\ln A, \ln T_{2}$, and $\ln T_{3}$ cannot pass the $t$-test, which means the results gained from the OLS method are questionable.

3.5. Partial Least Squares Regression (PLS) Method. Wold et al. $[34,35]$ proposed a new multivariate statistical analysis method to overcome multicollinearity, namely, partial least squares regression (PLS). It can be performed under the conditions of the existence of serious multiple correlations 
TABLE 3: Correlation matrix between variables.

\begin{tabular}{|c|c|c|c|c|c|c|c|c|c|}
\hline & $\ln I$ & $\ln \mathrm{P}$ & $\ln \mathrm{A}$ & $\ln \mathrm{T}_{1}$ & $\ln T_{2}$ & $\ln T_{3}$ & $\ln \mathrm{T}_{4}$ & $\ln I S$ & $\ln U \mathrm{~L}$ \\
\hline$\overline{\ln I}$ & 1.00 & & & & & & & & \\
\hline $\ln \mathrm{P}$ & $0.973^{* *}$ & 1.00 & & & & & & & \\
\hline $\ln \mathrm{A}$ & $0.961^{* *}$ & $0.960^{* *}$ & 1.00 & & & & & & \\
\hline $\ln \mathrm{T}_{1}$ & $-0.978^{* *}$ & $-0.940^{* *}$ & $-0.956^{* *}$ & 1.00 & & & & & \\
\hline $\ln \mathrm{T}_{2}$ & $-0.883^{* *}$ & $-0.797^{* *}$ & $-0.861^{* *}$ & $0.917^{* *}$ & 1.00 & & & & \\
\hline $\ln \mathrm{T}_{3}$ & $0.593^{* *}$ & $0.687^{* *}$ & $0.548^{* *}$ & $-0.515^{* *}$ & $-0.357^{*}$ & 1.00 & & & \\
\hline $\ln \mathrm{T}_{4}$ & $-0.521^{* *}$ & $-0.678^{* *}$ & $-0.60^{* *}$ & $0.494^{* *}$ & 0.288 & $-0.552^{* *}$ & 1.00 & & \\
\hline $\ln$ IS & $0.544^{* *}$ & $0.535^{* *}$ & $0.446^{* *}$ & $-0.430^{*}$ & -0.282 & $0.469^{* *}$ & $-0.348^{* *}$ & 1.00 & \\
\hline $\ln U L$ & $0.992^{* *}$ & $0.964^{* *}$ & $0.963^{* *}$ & $-0.980^{* *}$ & $-0.916^{* *}$ & $0.561^{* *}$ & $-0.539^{* *}$ & $0.494^{* *}$ & 1.00 \\
\hline
\end{tabular}

** Significant at $1 \%$ level.

${ }^{*}$ Significant at $5 \%$ level.

TABLE 4: Driving factors of carbon emissions by OLS.

\begin{tabular}{|c|c|c|c|c|c|c|}
\hline & Unstandardized coefficients & Std. error & Standardized coefficients & $t$-statistic & Sig. & VIF \\
\hline$C$ & -41.953 & 7.343 & & -5.713 & .000 & \\
\hline $\ln P$ & 3.977 & .732 & .465 & 5.434 & .000 & 108.463 \\
\hline $\ln A$ & .005 & .035 & .006 & .148 & .884 & 23.876 \\
\hline $\ln T_{1}$ & -1.320 & .365 & -.174 & -3.619 & .001 & 34.142 \\
\hline $\ln T_{2}$ & .503 & .361 & .060 & 1.393 & .177 & 27.473 \\
\hline $\ln T_{3}$ & -.605 & .518 & -.018 & -1.169 & .254 & 3.558 \\
\hline $\ln T_{4}$ & 1.235 & .139 & .133 & 8.897 & .000 & 3.295 \\
\hline $\ln$ IS & 1.077 & .243 & .053 & 4.436 & .000 & 2.087 \\
\hline $\ln \mathrm{UL}$ & 1.296 & .265 & .479 & 4.891 & .000 & 141.894 \\
\hline
\end{tabular}

Dependent variables: $\ln I$.

in the variables, and it contains all of the original variables in the final model. The main discrepancy between PLS method and ordinary multiple regression analysis is that PLS extracted a number of new synthetic variables (also called components) with the best explanatory ability for the system, rather than directly adopting the original variables set. The results obtained by PLS method, therefore, are more reliable and holistic.

The main principle of the PLS method is that the components $t_{1}$ and $u_{1}$ are extracted from the data tables of $X$ and $Y$, respectively. The components are totally independent of each other and should contain as much information as possible about the original variables. In addition, the correlation between the two should achieve a maximum.

After all the data were standardized, PLS implements the regression of $X$ to $t_{1}$ and $Y$ to $u_{1}$; if the satisfactory accuracy of the model has been achieved, the algorithm terminates; otherwise, the second regression analysis is implemented, and so forth, until satisfactory accuracy can be reached. PLS is an iterative algorithm built in; it is almost impossible to calculate by hand, and this study uses software SIMAC-P for this research.

The index Variable Importance for Projection (VIP) is used to judge the importance of every independent variable. It is generally believed that when VIP is larger than 1, the corresponding independent variables are important and when VIP is less than 0.5 , the independent variables are not important.

$$
\mathrm{VIP}_{j}=\sqrt{\frac{p}{R d\left(Y ; t_{1}, \ldots, t_{m}\right)}} \sum_{h=1}^{m} R d\left(Y ; t_{h}\right) * w_{h j}^{2} .
$$

In the above formula, $\mathrm{VIP}_{j}$ represents the VIP of $x_{j}(j=$ $1,2, \ldots, p) ; R d\left(Y ; t_{1}, \ldots, t_{m}\right)=\sum_{h=1}^{m} R d\left(Y ; t_{h}\right)$ means the accumulative capacity; $t_{1}, \ldots, t_{m}$ are principal components extracted from the variable $X, w_{h j}$ is the $j$ th component of the axis $w_{h}$, and it is used to measure the marginal contributions of $x j$ for the constitution of component $t_{h}$, and for any $h=$ $1,2, \ldots, m$,

$$
\sum_{j}^{p} w_{h j}^{2}=w_{h}^{\prime} w_{h}=1
$$

\section{Results and Discussion}

4.1. Model Results. Firstly, the goodness of fit of the model can be illustrated by two important tables or plots: the $t_{1} / t_{2}$ scatter plot (also called the $T^{2}$ oval plot) and $t_{1} / u_{1}$ scatter plot.

$T^{2}$ oval plot is used to observe the distribution of sample points and similarity structure in the plane; $t_{1}$ and $t_{2}$ carry the most information about the $X$ variable and can offer the 


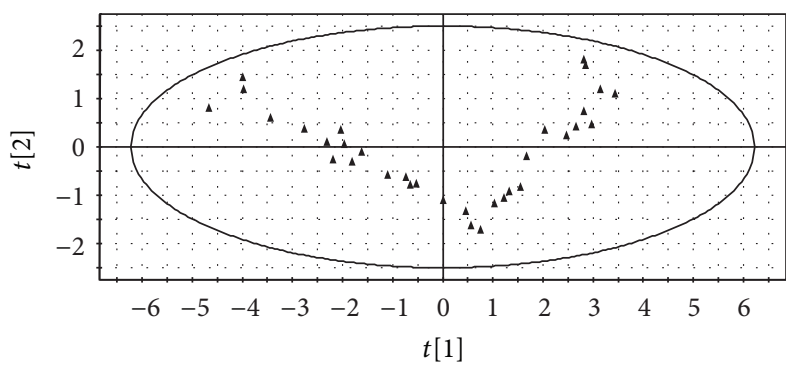

Figure 2: $T^{2}$ oval plot.

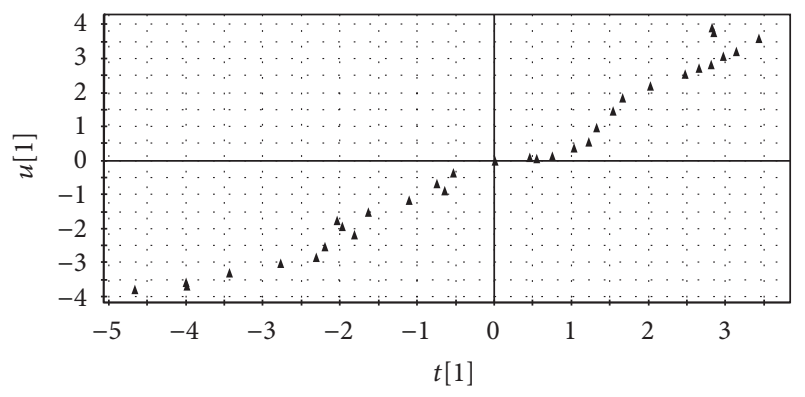

FIGURE 3: $t 1 / u 1$ scatter plot.

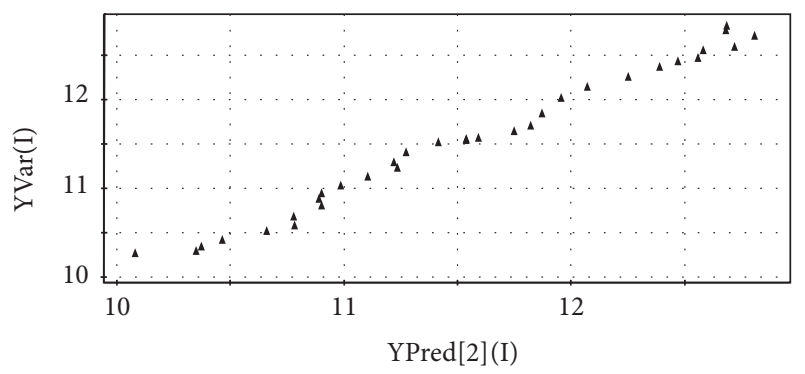

FIGURE 4: Scatter plots of predicted value and observed value of carbon emissions by PLS model.

greatest degree of interpretation of the $Y$ variables. If all the sample data are included in the $T^{2}$ oval plot, it indicates that there are no aberrance points, and the sample data can be accepted perfectly [36]. Obviously, all the sample points in this study are included in the oval (see Figure 2), and there is no need to make changes in the model.

In the $t_{1} / u_{1}$ scatter plot, if $t_{1} / u_{1}$ relationship is presented as near linear, the establishment of the model is reasonable [36]. It is clear from the illustration (Figure 3 ) that $t_{1}$ has a significant linear relationship with $u_{1}$; thus, $t_{1}$ and $u_{1}$ can well represent the variables $X$ and $Y$, respectively, and it is reasonable to establish the model by PLS.

In the scatter plots of predicted value and observed value of carbon emissions by PLS model (see Figure 4), if all of the data points are distributed in the vicinity of the diagonal, indicating that the difference between the predicted values and the original observations is very small, the fitting results are satisfactory [36]. It can be seen from Figure 4 that the original observations and the predicted values show good linear relationship, indicating that fitting of the model is ideal.
TABLE 5: The regression coefficients results of the PLS method.

\begin{tabular}{lccc}
\hline Components extracted & $t_{1}$ & $t_{1}$ and $t_{2}$ & $t_{1}, t_{2}$, and $t_{3}$ \\
\hline Constant & 14.315 & 14.315 & 14.315 \\
$\ln P$ & 0.171 & 0.175 & 0.201 \\
$\ln A$ & 0.169 & 0.178 & 0.169 \\
$\ln T_{1}$ & -0.172 & -0.208 & -0.216 \\
$\ln T_{2}$ & -0.155 & -0.199 & -0.158 \\
$\ln T_{3}$ & 0.104 & 0.042 & 0.05 \\
$\ln T_{4}$ & -0.092 & 0.019 & 0.06 \\
$\ln$ IS & 0.096 & 0.093 & 0.134 \\
$\ln$ UL & 0.175 & 0.203 & 0.214 \\
$R^{2} Y($ cum $)$ & 0.969 & 0.988 & 0.990 \\
$Q^{2}($ cum $)$ & 0.967 & 0.983 & 0.984 \\
\hline
\end{tabular}

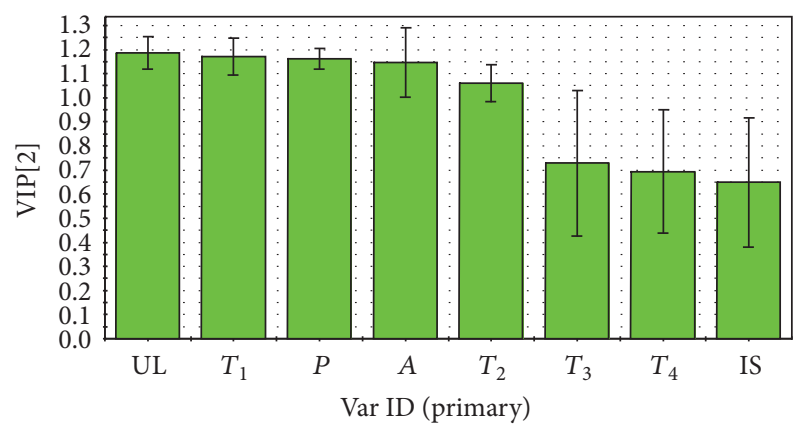

FIGURE 5: The VIP value of each variable in PLS method.

The index VIP is used to judge the importance of every independent variable; when VIP values are greater than 1 , the fact that corresponding variable plays a more important role in explaining the $Y$ variable can be considered. If the independent variable has a relatively small VIP index (less than 0.5 ), the fact that explanatory capability of the variable is not strong in the model is considered; the VIP values of UL, $T_{1}, P, A$, and $T_{2}$ are greater than 1 (see Figure 5). Among them, $\mathrm{UL}$ is the most important contributing factor.

$R^{2} Y$ (cum) represents the cumulative explanatory capacity of the principal components extracted from the original $Y$ variable to the original $Y$ variables. $Q^{2}$ (cum) represents the cumulative cross validation. Generally speaking, when the two indicators are all greater than 0.8 , the results generated by the model are effective. The coefficient of $\ln P$ was 0.171 after the principal component $t_{1}$ was extracted (Table 5). When $t_{1}$ and $t_{2}$ were extracted, the coefficient becomes 0.175 ; when $t_{1}, t_{2}$, and $t_{3}$ were all extracted, the coefficient became 0.20 , which indicated that a $1 \%$ change in the population would cause a $0.171 \%-0.201 \%$ change in the $\mathrm{CO}_{2}$ emissions. That is, $P$ had an elasticity of $0.171-0.201$. When two principal components $t_{1}$ and $t_{2}$ were considered, $P, A, T_{1}, T_{2}$, and UL had an elasticity of $0.175,0.178,-0.208,-0.199$, and 0.203 , respectively. The regression coefficients and the VIP value of each variable have good consistency. Therefore, $P$, $A, T_{1}, T_{2}$, and UL could be the major drivers of the carbon emissions. The coefficients of $T_{3}, T_{4}$, and IS were very small 
$(<0.1)$; thus they might have little impact on the carbon emissions.

4.2. Variable Importance Discussion. According to the model coefficients and the VIP values of the variables (see Figure 5), $P, A, T_{1}, T_{2}$, and UL might be the major drivers of carbon emissions $(Y)$. The impact of $T_{3}, T_{4}$, and IS on carbon emissions $(Y)$ could not be determined or was not important. The specific analysis is as follows.

(1) Urbanization level has the strongest positive influence on the performances of carbon emissions within power sector, mainly because there exists a highly positive correlation between urbanization and the growth of power demand. Generally speaking, the energy consumption of one urban resident is three times more than that of one rural resident in China. The urbanization level in China increased by nearly $30 \%$ to reach $53.73 \%$ from 1981 to 2013 , and the annual average increased by $1.05 \%$, but it was still $30 \%-70 \%$ of the rapid development in urbanization urbanization rate. In the process of urbanization rate from $50 \%$ to $70 \%$, a $1 \%$ increase in urbanization rate, the total electricity consumption increased by an average of $4.6 \%$ [37]. The electricity consumption and urbanization rates in developing countries are mainly related to exponential growth, but in developed countries the two rates present a logistic growth curve model, and there are signs of the saturation of power demand.

(2) The technical indicators $T_{1}$ "standard coal consumption per power generation" and $T_{2}$ "line loss rate" both have strong explanatory power for carbon emissions. The former has the most obvious inhibitory effects, indicating that technological progress is still the vital means for achieving emissions reductions in China's power sector. This finding is the same as the studies of some previous scholars $[9,11]$. The coal consumption rate continued to show a downward trend, falling from $442 \mathrm{~g} / \mathrm{kWh}$ in 1981 to $302 \mathrm{~g} / \mathrm{kWh}$ in 2013, and it is related to the national policy and development tactic. The line loss rate is the second major driving factor in inhibiting carbon emissions from the power industry, decreasing from $9 \%$ in 1981 to $6.7 \%$ in 2013 . Because the electricity production and consumption are large, losses in transmission and distribution cannot be ignored. The power losses in transmission and distribution in China amounted to 289.616 TWh in 2012 or more than two years of electricity consumption in Shanghai in the current year. Although China has increased its investment in the construction and development of power grids, some cities still have outdated and aging power equipment.

(3) Growth in population is also an important contributor to carbon emissions. First, population growth will boost demand for electricity generation; second, electrification has improved the use of household appliances, most of which are domestically produced; thus, manufacturing will drive the demand for electricity generation. China has always been a country with a large population, and although the onechild policy led to a lower growth rate of the population, the total population still shows a growing trend. The population rate in China has been growing at close to $1 \%$ per annum during 1981-2013. Chinese thermal power generation has

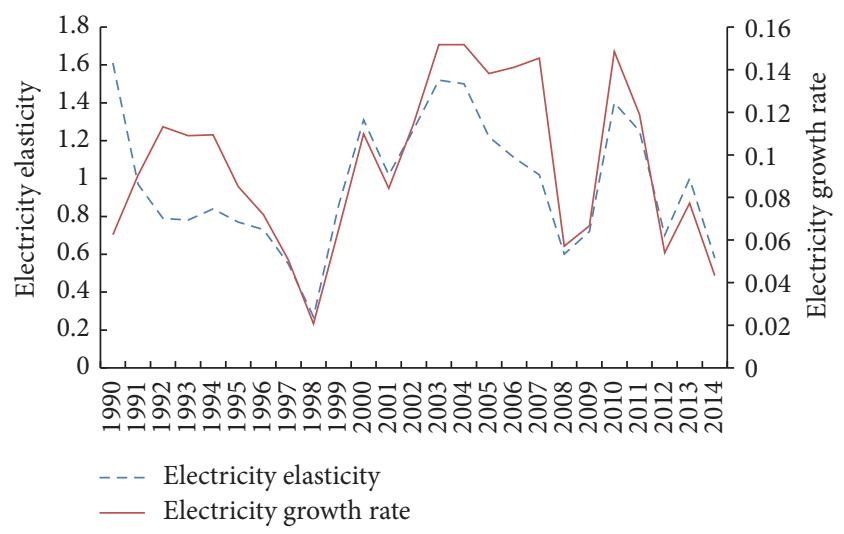

FIGURE 6: Electricity growth rate and electricity elasticity in China, 1990-2014 (the China Statistic Yearbook).

risen by an average of $9.32 \%$ annually on the same time; its growth rate was significantly higher than the former. China's annual $\mathrm{CO}_{2}$ emissions per person have reached 6 tonnes, and some of the developed eastern regions have reached 10 tonnes, showing a sustained growth trend $[38,39]$. This growth has approached the peak $\mathrm{CO}_{2}$ emissions of Europe, Japan, and other developed countries, and it can be predicted that the carbon emissions from power sector will maintain their growth trend with the increase in the total population in China.

(4) Different from the conclusions that have been reached in some papers [9], economic activities are not the most important contributor in promoting carbon emissions from power sector in China. Understanding the relationship between economic growth and electricity demand is essential for power system planning. Qiu and Dong [40] thought that there is a strong connection between power consumption and economic development; however, "decoupling" phenomenon of these occurs at a specific time. The growth rate of electricity production in China has been substantially synchronized with the electricity elasticity coefficient (see Figure 6) from 1990 to 2014, and a small decline could be seen in the electricity elasticity coefficient from 2013 . The average annual electricity growth speed was $5.7 \%$ in China during the "Twelfth Five-Year Plan" (from 2011 to 2015) period, with an overall slowdown of nearly $50 \%$, compared with an average of 11\% during "Eleventh Five-Year Plan" (from 2006 to 2010) period, suggesting that as China's economy has entered a phase of low growth in the past two years, electricity consumption has slowed down a lot.

(5) The weakest relationship exists between industrial structure and carbon emissions from power sector. As the adjustment of second industries has not been obvious from 1981 to 2013. The proportion of second industries in total industry decreased from $45.81 \%$ in 1981 to $43.67 \%$ in 2013 , presenting a small change in the float.

\section{Conclusions and Policy Implications}

With the significant increase of carbon emissions from the power sector, it should be given the priority by policy makers. 
This paper examines the impacts of seven factors from different aspects on carbon emissions within power sector from 1981 to 2013 using the STIRPAT model. The empirical results determined by PLS method indicated that the main drivers from strong to weak were as follows: urbanization level (UL) $>$ technology level $\left(T_{1}\right)>$ population $(P)>$ GDP per capita $(A)>$ line loss $\left(T_{2}\right)>$ power generation structure $\left(T_{3}\right)>$ energy intensity $\left(T_{4}\right)>$ industry structure (IS). Different from the previous conclusions, economic activities were no longer the most significant contribution factor, implying that as the economy loses its power, the strong correlation between electricity demand and economic growth weakened. Industrial structure has the minimum impact on carbon emissions from the power sector, because the adjustment of second industries has not been obvious over the past three decades. Urbanization level was the most significant, positive driving factor, and the technical indicators "coal consumption rate" and "line loss rate" both had strong explanatory power for carbon emissions from the power sector; the former had the most obvious inhibitory effect, indicating that technological progress is still the vital means to achieve emissions reduction in China.

According to the above analysis, policy implications are proposed for the future development of the power sector.

(1) Improving the Low-Carbon Development Model of Urbanization. Both population size and urbanization level have important impacts on the $\mathrm{CO}_{2}$ emissions from the power industry; in particular, the urbanization level has the greatest impact. The government should continue to control the population size and further improve the low-carbon development model of urbanization, specifically including the promotion of low-carbon urbanization fiscal policies, the strengthening of the application of market instruments, and the guiding of low-carbon lifestyles for residents. There exists a highly positive correlation of the urbanization rate with electricity demand growth, and the growth laws are different in the early, middle, and late stages. Therefore, special attention should be paid scientifically to the electricity load changes caused by rural populations transferring to cities, as well as the medium/long-term forecasts.

(2) Accelerating the Development of Low-Carbon Power Technology. Clean coal technology is one of the dominant technologies to solve environmental problems worldwide, such as the ultrasupercritical (USC) units, the integrated coal gasification combined cycle power generation (IGCC), and the circulating fluidized bed (CFB), which should be comprehensively promoted in the construction of thermal power units. Carbon capture and storage (CCS) technology will be the single largest share of emissions reduction technology in the future, while CCS technology is still in preliminary stages in China currently; thus policy makers should focus their efforts on development and application. At least 60 types of key technical support were needed to achieve lowcarbon economy, 42 of which China has not yet mastered; that is, $70 \%$ of the core technology needs to be imported. Technical options, to a certain degree, determine the future of emission levels in China, so the government should actively strengthen international cooperation in low-carbon technologies with developed countries, providing a positive development environment for China's power industry.

(3) Improving Power Transmission Efficiency and Strengthening Smart Grid Construction. To further optimize the power structure, according to the National Energy Administration, we should control the coal-fired power installed capacity within $1100 \mathrm{GW}$ and vigorously develop new energy sources such as hydropower and nuclear power. In addition, the renewable energy acceptance and absorptive intensity should also be strengthened from the power grid construction. Smart grid can improve the cross level resource scheduling and enhance the transmission capacity of power grid. The optimization of the grid structure can fully replace energy-saving equipment with high energy consumption and high-loss products, minimizing power consumption in the transportation process. In brief, smart grids are a win-win choice because they provide a platform for both private users and companies to interact with the grid. Strengthening demand side management will effectively reduce the power consumption intensity and carbon emissions from the power sector while helping users achieve energy management to establish a low-carbon and energy-efficient lifestyle.

\section{Conflicts of Interest}

The authors confirm that the mentioned received funding in Acknowledgments did not lead to any conflicts of interest regarding the publication of this manuscript. And the authors declare there are no conflicts of interest in the manuscript.

\section{Acknowledgments}

This work was supported by the grant from the National Natural Science Foundation of China (no. 71173200), the Development and Research Center of China Geological Survey (no. 12120114056601 and no. 12120113093200), and National Science and Technology Major Project (no. 2016ZX05016005003). In addition, the authors would like to appreciate Professor Campbell from Michigan Technological University for his comments and suggestions.

\section{References}

[1] IEA, $\mathrm{CO}_{2}$ Emissions from Fuel Combustion 2014: OECD/IEA, OECD/IEA, Paris, France, 2014.

[2] World Development Indicators, 2012, http://data.worldbank .org/datacatalog/world-development-indicators.

[3] Xinhua, U. S. China Joint Announcement on Climate Change, 2014 (Chinese), http://news.xinhuanet.com/energy/2014-11/13/ c_127204771.htm.

[4] SCIO (The State Council Information Office of the People's Republic of China), "National response to climate change program (2014-2020)," 2014, (Chinese) http://www.scio.gov.cn/ xwfbh/xwbfbh/wqfbh/2014/20141125/xgzc32142/Document/1387125/1387125_5.htm. 
[5] R. M. Shrestha, G. Anandarajah, and M. H. Liyanage, "Factors affecting $\mathrm{CO}_{2}$ emission from the power sector of selected countries in Asia and the Pacific," Energy Policy, vol. 37, no. 6, pp. 2375-2384, 2009.

[6] S. Malla, " $\mathrm{CO}_{2}$ emissions from electricity generation in seven Asia-Pacific and North American countries: a decomposition analysis," Energy Policy, vol. 37, no. 1, pp. 1-9, 2009.

[7] P. A. Steenhof and C. J. Weber, "An assessment of factors impacting Canada's electricity sector's GHG emissions," Energy Policy, vol. 39, no. 7, pp. 4089-4096, 2011.

[8] J. Hou and Z. Tan, "The factor decomposition of $\mathrm{CO}_{2}$ emission changes in electricity production in China," Electric Power, vol. 44, no. 11, pp. 39-42, 2011 (Chinese).

[9] M. Zhang, X. Liu, W. Wang, and M. Zhou, "Decomposition analysis of $\mathrm{CO}_{2}$ emissions from electricity generation in China," Energy Policy, vol. 52, pp. 159-165, 2013.

[10] X. Zhao, Q. Ma, and R. Yang, "Factors influencing $\mathrm{CO}_{2}$ emissions in China's power industry: co-integration analysis," Energy Policy, vol. 57, pp. 89-98, 2013.

[11] L. Yang and B. Lin, "Carbon dioxide-emission in China's power industry: evidence and policy implications," Renewable and Sustainable Energy Reviews, vol. 60, pp. 258-267, 2016.

[12] M. Karmellos, D. Kopidou, and D. Diakoulaki, "A decomposition analysis of the driving factors of $\mathrm{CO}_{2}$ (Carbon dioxide) emissions from the power sector in the European Union countries," Energy, vol. 94, pp. 680-692, 2016.

[13] A. R. Noorpoor and S. N. Kudahi, " $\mathrm{CO}_{2}$ emissions from Iran's power sector and analysis of the influencing factors using the stochastic impacts by regression on population, affluence and technology (STIRPAT) model," Carbon Management, vol. 6, no. 3-4, pp. 101-116, 2015.

[14] Xinhua, The 13th Five Year Plan for national economic and social development of the People's Republic of China, 2016 (Chinese), http://news.xinhuanet.com/politics/2016lh/2016-03/17/ c_1118366322_13.htm.

[15] China Electricity Council (CEC), The Current Status and Prospect of China's Power Industry, China Electricity Council, Beijing, China, 2015 (Chinese), http://www.cec.org.cn/yaowenkuaidi/2015-03-10/134972.html.

[16] T. Fan, R. Luo, H. Xia, and X. Li, "Using LMDI method to analyze the influencing factors of carbon emissions in China's petrochemical industries," Natural Hazards, vol. 75, no. S2, pp. 319-332, 2015.

[17] X. Ouyang and B. Lin, "An analysis of the driving forces of energy-related carbon dioxide emissions in China's industrial sector," Renewable and Sustainable Energy Reviews, vol. 45, pp. 838-849, 2015.

[18] B. Lin and H. Long, "Emissions reduction in China's chemical industry-based on LMDI," Renewable and Sustainable Energy Reviews, vol. 53, pp. 1348-1355, 2016.

[19] H. Li, H. Mu, M. Zhang, and N. Li, "Analysis on influence factors of China's $\mathrm{CO}_{2}$ emissions based on Path-STIRPAT model," Energy Policy, vol. 39, no. 11, pp. 6906-6911, 2011.

[20] S. Lin, D. Zhao, and D. Marinova, "Analysis of the environmental impact of China based on STIRPAT model," Environmental Impact Assessment Review, vol. 29, no. 6, pp. 341-347, 2009.

[21] Y. Fan, L.-C. Liu, G. Wu, and Y.-M. Wei, "Analyzing impact factors of $\mathrm{CO}_{2}$ emissions using the STIRPAT model," Environmental Impact Assessment Review, vol. 26, no. 4, pp. 377-395, 2006.

[22] Z. Wang, F. Yin, Y. Zhang, and X. Zhang, "An empirical research on the influencing factors of regional $\mathrm{CO}_{2}$ emissions: evidence from Beijing city, China," Applied Energy, vol. 100, pp. 277-284, 2012.

[23] Q. Zhu and X. Peng, "The impacts of population change on carbon emissions in China during 1978-2008," Environmental Impact Assessment Review, vol. 36, pp. 1-8, 2012.

[24] C. Zhao, B. Chen, T. Hayat, A. Alsaedi, and B. Ahmad, "Driving force analysis of water footprint change based on extended STIRPAT model: evidence from the Chinese agricultural sector," Ecological Indicators, vol. 47, pp. 43-49, 2014.

[25] J. Huo, D. Yang, W. Zhang, F. Wang, G. Wang, and Q. Fu, "Analysis of influencing factors of $\mathrm{CO}_{2}$ emissions in Xinjiang under the context of different policies," Environmental Science and Policy, vol. 45, pp. 20-29, 2015.

[26] Y. Wang and T. Zhao, "Impacts of energy-related $\mathrm{CO}_{2}$ emissions: evidence from under developed, developing and highly developed regions in China," Ecological Indicators, vol. 50, pp. 186-195, 2015.

[27] B. Li, X. Liu, and Z. Li, "Using the STIRPAT model to explore the factors driving regional $\mathrm{CO}_{2}$ emissions: a case of Tianjin, China," Natural Hazards, vol. 76, no. 3, pp. 1667-1685, 2015.

[28] Y. Qi and X. Zhang, Annual Review of Low-Carbon Development in China (2015-2016), Social Sciences Academic Press, Beijing, China, 2016 (Chinese).

[29] IPCC, IPCC Third Assessment Report: Climate Change 2006, Cambridge University Press, Cambridge, UK, 2006.

[30] P. R. Ehrlich and J. P. Holdren, "Impact of population growth," Science, vol. 171, no. 3977, pp. 1212-1217, 1971.

[31] P. C. Schulze, “I = PBAT," Ecological Economics, vol. 40, no. 2, pp. 149-150, 2002.

[32] P. E. Waggoner and J. H. Ausubel, "A framework for sustainability science: a renovated IPAT identity," Proceedings of the National Academy of Sciences of the United States of America, vol. 99, no. 12, pp. 7860-7865, 2002.

[33] T. Dietz and E. A. Rosa, "Rethinking the environmental impacts of population, affluence and technology," Human Ecology Review, vol. 1, pp. 277-300, 1994.

[34] S. Wold, H. Martens, and H. Wold, "The multivariate calibration problem in chemistry solved by the PLS method," in Matrix Pencils, vol. 973 of Lecture Notes in Mathematics, pp. 286-293, Springer, Berlin, Germany, 1983.

[35] S. Wold, C. Albano, M. Dunn et al., Pattern Regression Finding and Using Regularities in Multivariate Data, Analysis Applied Science Publication, London, UK, 1983.

[36] H. W. Wang, Z. B. Wu, and J. Meng, Partial Least-Squares Regression-Linear and Nonlinear Methods, National Defense Industry Press, Beijing, China, 2006 (Chinese).

[37] X. Xiao, Y. Zhou, and N. Zhang, "Study on the relationship between urbanization process and electricity demand growth," Electric Power, vol. 48, no. 2, pp. 145-149, 2015 (Chinese).

[38] China Electricity Council (CEC), Du Xiangwan: Low Carbon Power Has the Future, China Electricity Council, Beijing, China, 2015 (Chinese), http://www.cec.org.cn/huanbao/zhuanjiaguandian/2015-04-07/136164.html.

[39] Z. E. Zhang, Y. F. Yan, L. Zhang, and S. X. Ju, "Hollow fiber membrane contactor absorption of $\mathrm{CO}_{2}$ from the flue gas: review and perspective," Global Nest Journal, vol. 16, no. 2, pp. 355-374, 2014.

[40] W.-J. Qiu and S.-W. Dong, "Econometric analysis on power consumption and correlated factors," Journal of North University of China (Natural Science Edition), vol. 28, no. 2, pp. 151-155, 2007 (Chinese). 


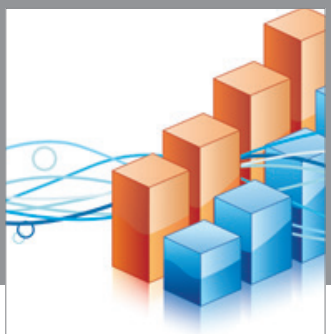

Advances in

Operations Research

vatem alat4

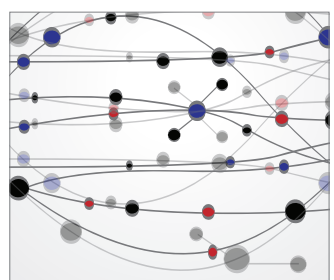

\section{The Scientific} World Journal
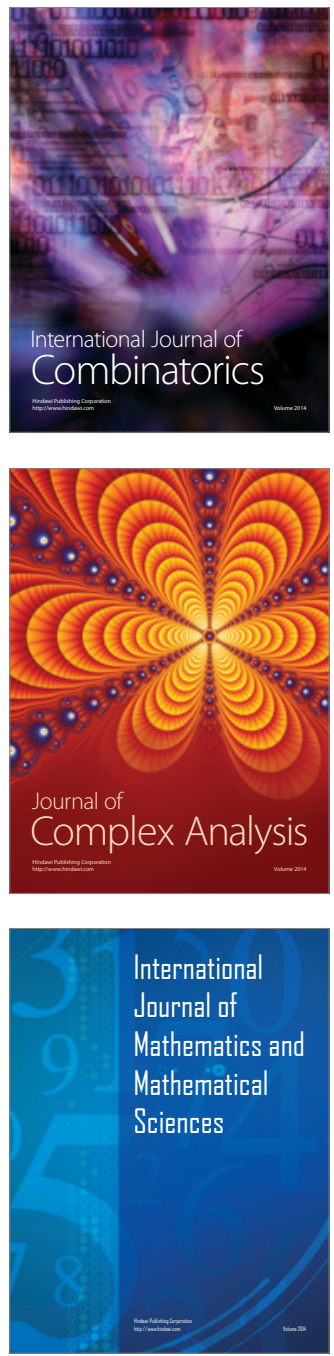
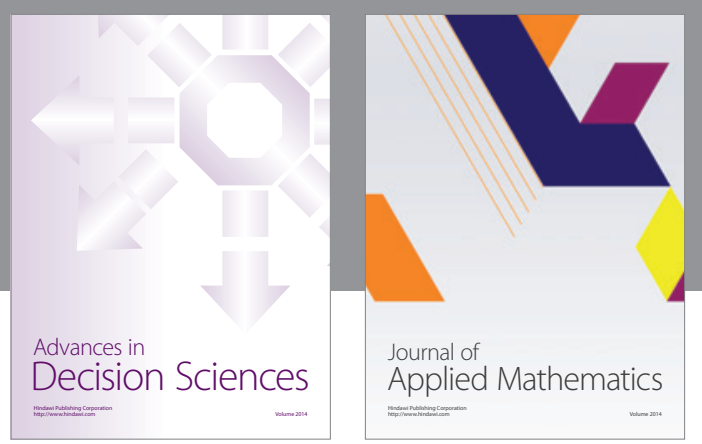

Algebra

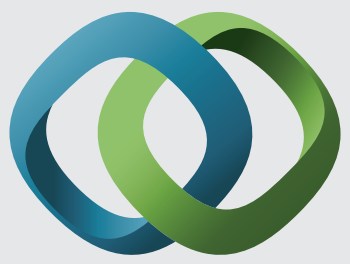

\section{Hindawi}

Submit your manuscripts at

https://www.hindawi.com
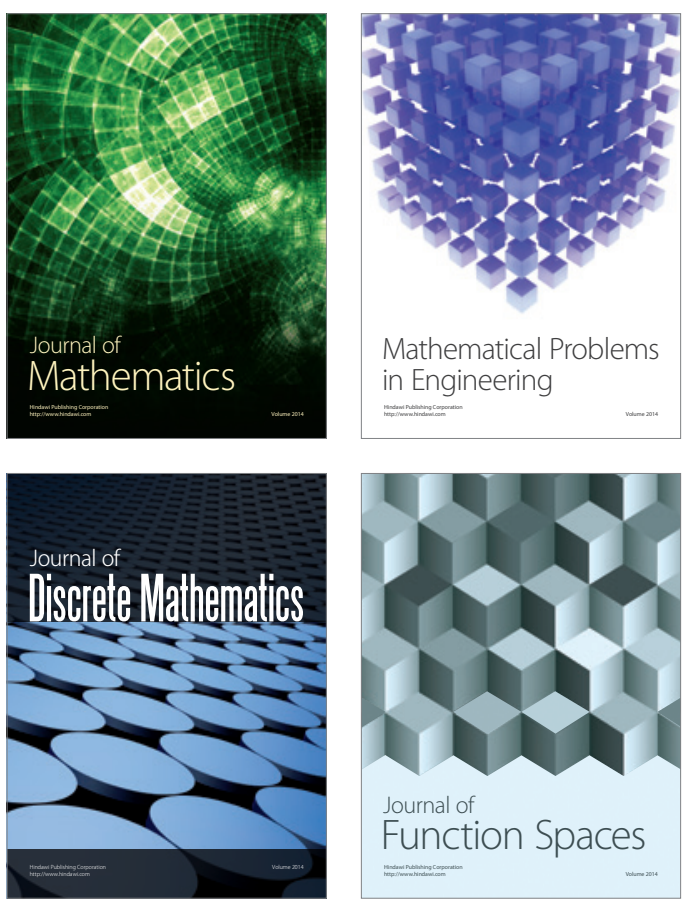

Mathematical Problems in Engineering
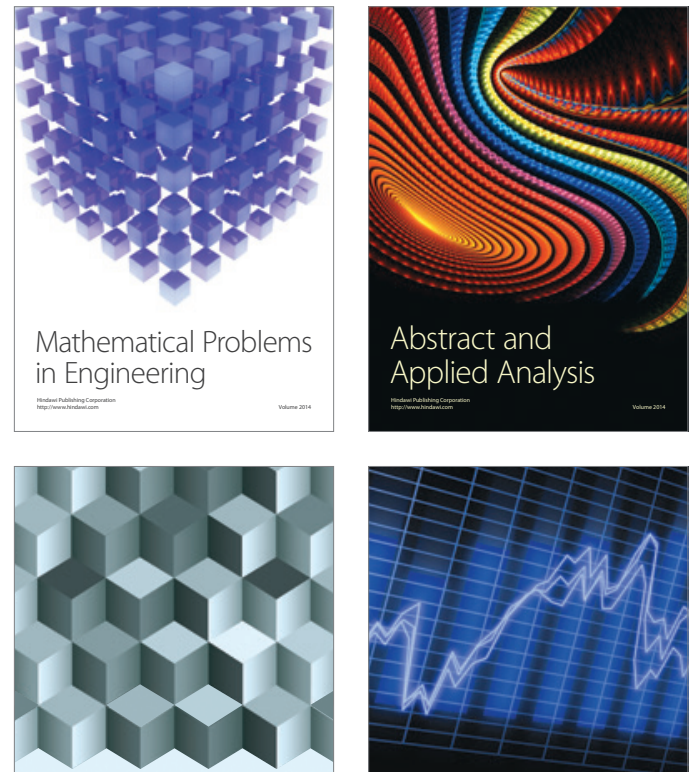

Journal of

Function Spaces

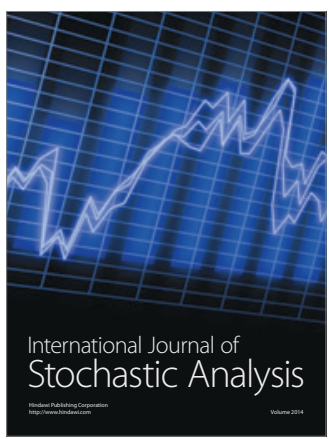

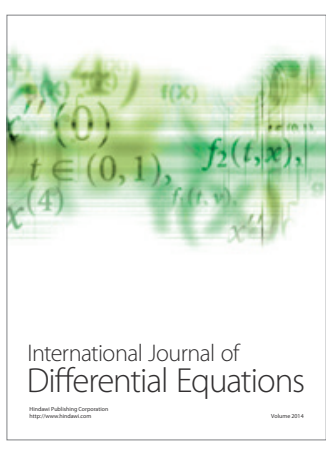
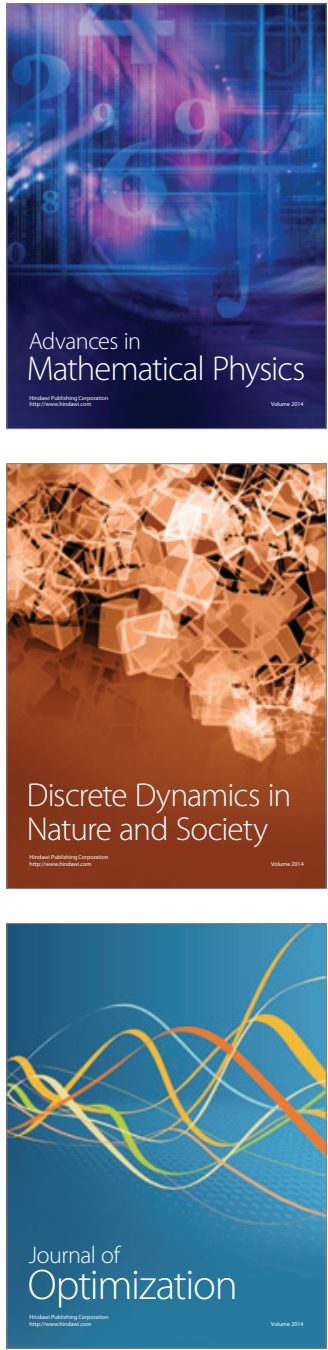